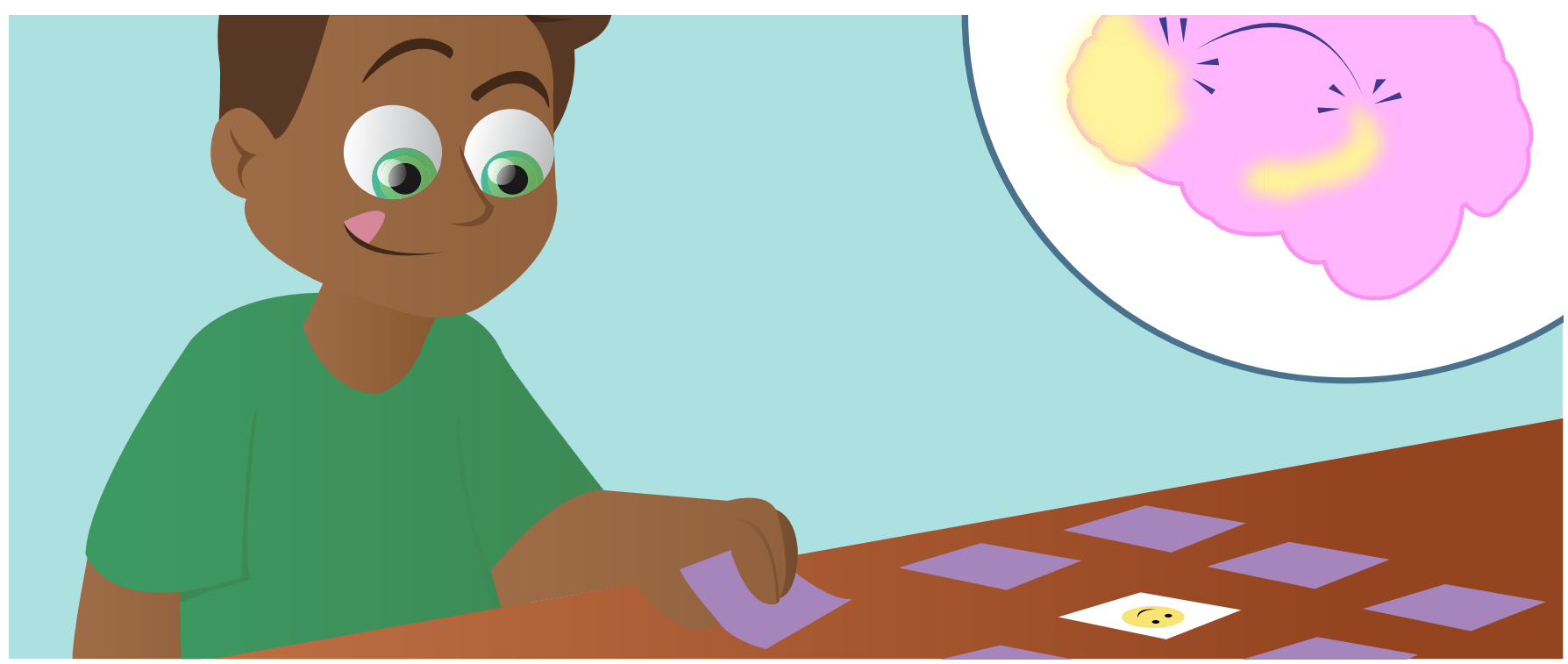

\title{
THE JUMP-ROPING BRAIN
}

\section{Kate R. Zha, Jennifer Hyman and James M. Hyman*}

H.i.v.E. Laboratory, Department of Psychology, University of Nevada, Las Vegas, Las Vegas, NV, United States

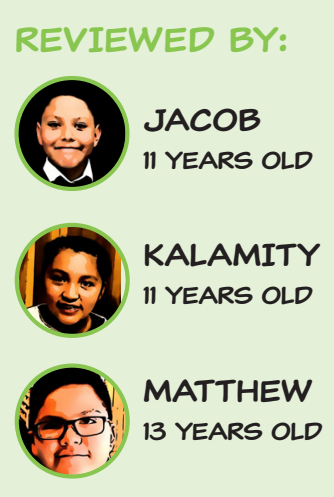

Different parts of the brain work together to help us solve problems, play, and pay attention in school. Every task we do is broken down into smaller tasks that different parts of the brain are responsible for completing. To successfully accomplish these tasks, the different parts of the brain need to work together to "share" information. We were interested in how information was shared between brain areas while rats played a memory game. We found that two parts of the brain, called the medial prefrontal cortex and the hippocampus, had to work together in order for the rats to play the game correctly. When these two brain areas were synchronized, the rats played the game correctly, but when these two areas were out of sync and thus could not "share" their information, the rats got the problem wrong and did not play the game correctly.

\section{INTRODUCTION: GRAB SOME FRIENDS}

Imagine you are playing jump rope with your friends. Two of your friends are turning the ropes as you jump in the middle. Every time you jump up, a rope goes under your feet. Every time you go down, the ropes are above you. The game is continuing because you are jumping at the same rhythm that your friends are turning the ropes (see Figure 1A). 


\section{FIGURE 1}

The jump-rope game.

A. The girl wearing the blue dress and the boy with the yellow shirt are spinning the ropes in rhythm, so that the girl wearing the purple shirt can jump up and down.

B. The boy wearing the red shirt joins the game but does not jump at the same rhythm as the girl jumping in $\mathbf{A}$. so the game ends.
MEDIAL

PREFRONTAL

\section{CORTEX (MPFC)}

The part of the brain that holds information needed for solving problems.

HIPPOCAMPUS (HC)

The part of the brain that helps remember where things are located.

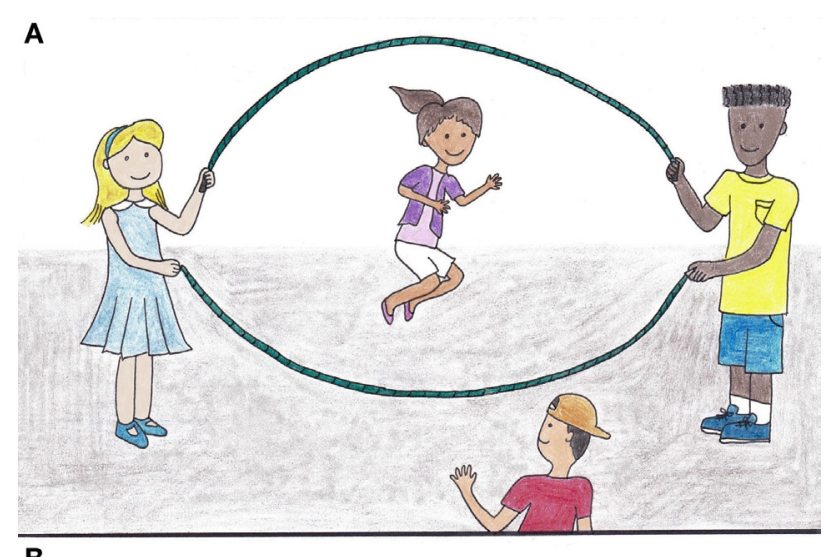

B

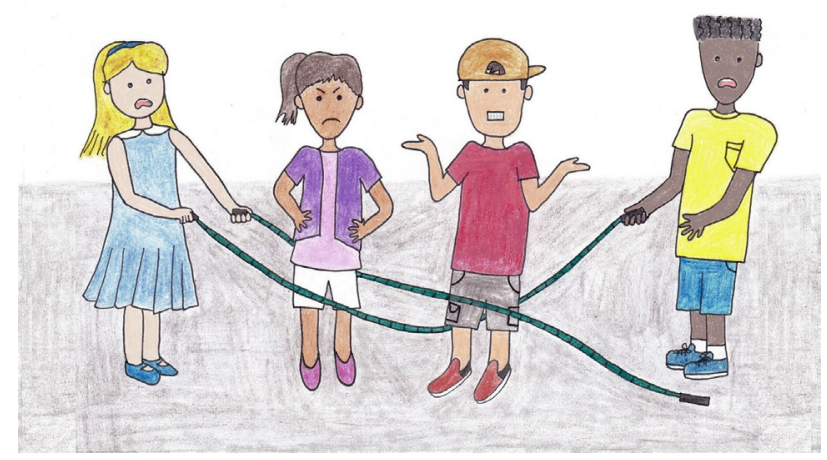

FIGURE 1

Another friend wants to join your game and tries to jump in. If he does not jump at the same rhythm as you, then your friend will trip over a rope and cause the game to stop (see Figure 1B). If, however, your friend does jump at the same rhythm, you and your friend can continue going up and down at the same time, and the game will last as long as you continue to jump together.

Another way to think about the jump-rope game is that it is like the beat of a song. For multiple instruments and vocals to come together to form a good song, they all must be in rhythm. For an instrument to join in to the song, it must follow the beat; likewise, for your friend to join in the game of jump rope, he must jump in at the right time.

The brain works the same way. Brain areas process information by keeping everything in rhythm. Just like separate musicians in a band play different instruments and then add the sounds together to make a song, separate parts of the brain process different types of information and then add the data together to complete tasks, such as remembering where things are, successfully. These brain processes allow us to see, hear, feel, think, and move. In this article, we talk about a part of the brain called the medial prefrontal cortex (mPFC) that can work, or "play" at the same rhythm as another part of the brain called the hippocampus (HC). Figure 2 shows where the mPFC (in red) and $\mathrm{HC}$ (in blue) are located in a human brain and in a rat brain. 
FIGURE 2

Location of the medial prefrontal cortex (mPFC) and hippocampus $(\mathrm{HC})$ in a human brain and a rat brain. In both brains, the $\mathrm{mPFC}$ is colored red, while the HC colored blue. You can see the locations of the $\mathrm{mPFC}$ and the $\mathrm{HC}$ are similar in the brains of humans and rats.
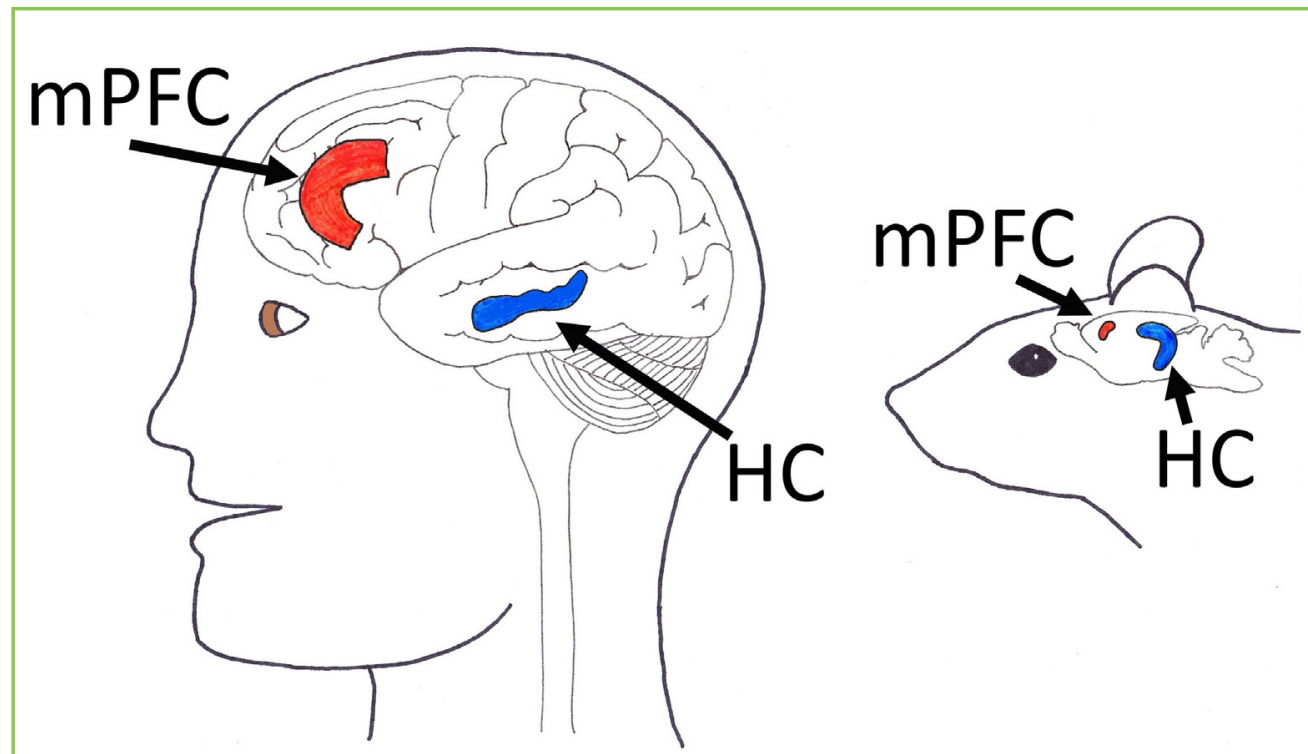

FIGURE 2

The mPFC holds information we might need in the near future for solving problems (like remembering what something looks like) while the HC helps remember where things are. The rhythm these two areas share is called the hippocampal theta rhythm. You can think of the theta rhythm as the beat of a song or the swings of a jump rope.

For two brain areas to share information, the neurons (nerve cells) in those areas need to send messages on-beat. This is like the example we gave of your friend needing to jump on-beat in the jump-rope game. When neurons share information with other neurons, we call this firing-a process where cells in the brain send (fire) electrical impulses to other brain cells. When we talk about the mPFC working at the same beat as the hippocampal theta rhythm, we mean the mPFC cells are firing in sync with this rhythm. However, sometimes these same neurons in the MPFC are not on-beat with the hippocampal theta rhythm, so they fire out of sync and information is not shared with the HC. Cells firing out of rhythm are like an instrument joining into a song off-beat and disrupting the whole song.

Different parts of the brain working together are like friends playing a game of jump rope or a band of musicians playing a song. In our experiment, we were interested in how and why the MPFC and HC work at the same rhythm to help solve memory problems. It is difficult to do experiments on the brains of humans, so we used rats as our test animal. Our hypothesis, or the idea that we were testing, was that when the cells in a rat's mPFC were in rhythm with cells in its $\mathrm{HC}$, the rat would correctly solve memory problems. In addition, we believed that when the rhythm was lost, the rat would get the answer wrong. 


\section{ELECTROPHY- SIOLOGY}

The study of electrical activity in the body (in our case, in the brain).

\section{EXPERIMENTAL \\ CHAMBER}

A specific area (like a box) where an experiment takes place.

\section{DELAY PERIOD}

A controlled amount of time between when the rat is shown the levers and when it chooses which lever to push.

\section{FIGURE 3}

Rat behavior during the experiment when medial prefrontal cortex neurons are firing to the hippocampal theta rhythm. A. The rat pushes in the extended lever on the right. B. As the rat runs to the other side of the experimental chamber, it remembers which lever it pushed. C. When the rat returns to the levers, both of them are extended.

The rat again remembers which lever was pushed the first time. D. The rat chooses and pushes the opposite lever and receives a sweet pellet from the reward dispenser.

\section{METHODS: HOW TO PLAY}

For our experiment, we used a technique called electrophysiology to record the brain activity of rats that were solving a memory problem, so that we could see how different parts of the brain acted during the experiment. Electrophysiology allowed us to capture both the electrical impulses, or firing, of individual brain cells in the MPFC as well as the background rhythms (like the theta rhythm), which we call neuronal oscillations, in the HC. This way, we could measure how the MPFC and HC were acting, both separately and together.

For the task, we had the rats play a game in which they needed to press levers in a certain order to get a sweet treat. There were two levers in the experimental chamber, one on the left and one on the right. The rats needed to switch between pressing the left and right levers within each trial. First, we showed the rats that one of the levers was pushed in (retracted) and the other was sticking out (extended) (Figure 3A). We trained the rats to first push in the extended lever. Then, they had to run to the other side of the chamber. This was called the delay period, and during this time the rats needed to remember which lever they had just pushed. For the last stage of the task, the rats had to run back to the two levers and press the other lever-the one they did not press before. If they did this, then they got a sugary treat. However, if they pushed the wrong lever, then they did not get a treat.

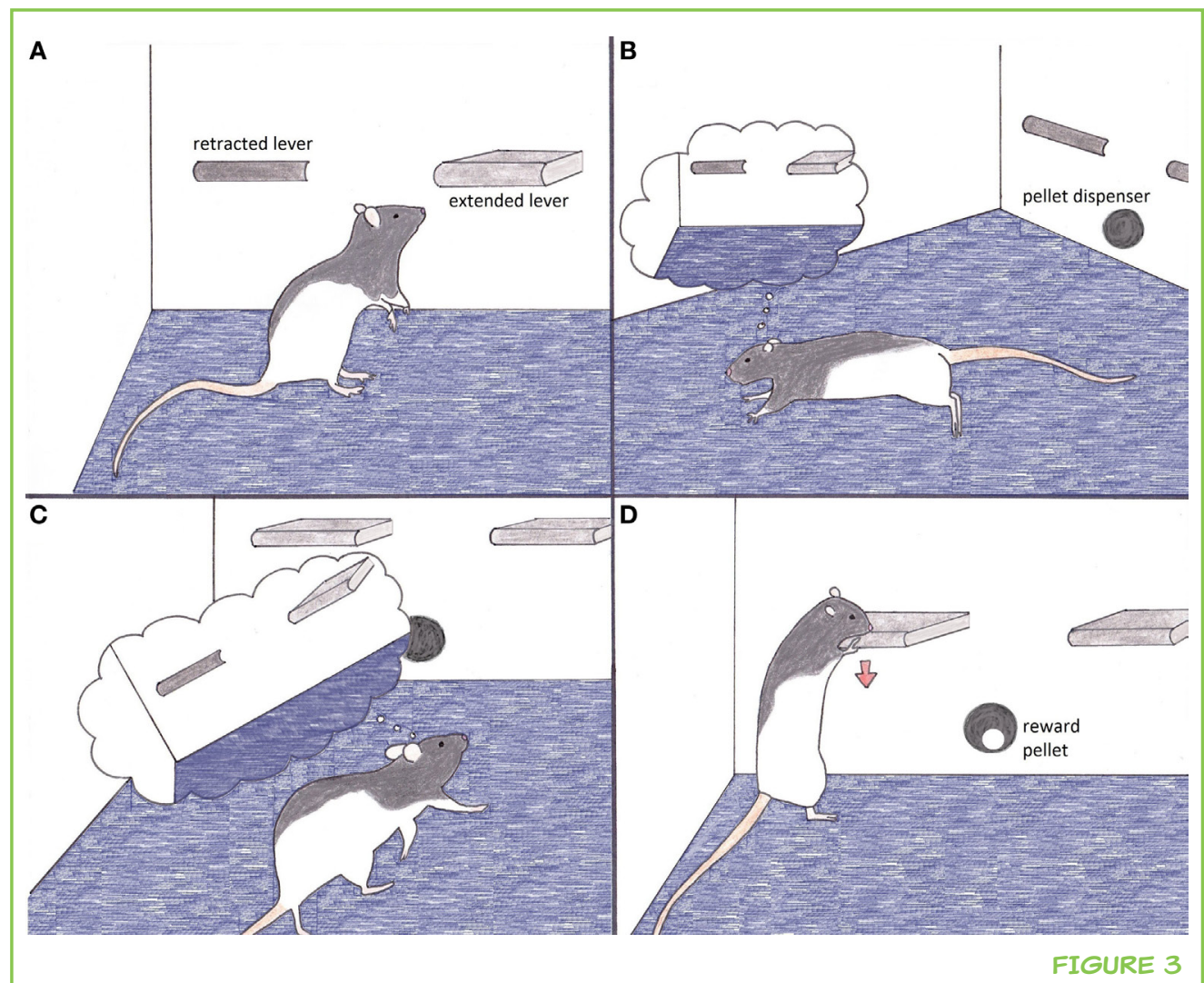


For example, look at the rat in Figure 3. In Figure 3A, he presses the extended lever on the right. Then, in Figure 3B, he runs away from the levers but still remembers what they look like. When he comes back to the levers again in Figure 3C (now both extended), he thinks back and remembers that he pressed the right lever earlier. In Figure 3D, the rat compares his memory to what he sees in real life and chooses the left lever, just as he was trained to do. This earns him a sugary reward pellet.

Although it may seem like a short period of time, the delay period when the rat runs from one side of the chamber to the other and back again is actually quite challenging. Try for yourself by laying out two pencils in front of you. Pick up the pencil on the left and bring the eraser to the tip of your nose, then place it back down. Wait 30 seconds and then pick up and put down the pencil on the right in the same way you did the first. Continue switching between picking up the two pencils every 30 seconds. This task will be easy at first, but after a few tries, you will probably start to make some mistakes. The more you do this, the more likely you are to confuse the pencil you picked last time with the one you picked two or three or four times ago. Our rats performed in the same way, although they did well overall and selected the correct lever about $85 \%$ of the time! It seems rats and humans can be similar, not only in brain structure (as shown in Figure 2) but also in behavior.

The electrophysiological measurements of the mPFC and $\mathrm{HC}$ of the rats doing the task in Figure 3 were analyzed to answer our questions about how and why the mPFC and HC work together to solve problems. Specifically, we looked to see if our hypothesis was accurate. When the rats successfully played the game and thus got a treat, were the cells in the MPFC in rhythm with the oscillations in the HC? On the other hand, if a rat happened to push the wrong lever during the last stage of the task, would we see that the cells in the mPFC were not in rhythm with the hippocampal theta rhythm?

\section{RESULTS: DO NOT MISS A BEAT}

Remember from the introduction that the mPFC holds specific memories about things that we might need to use in the near future. The HC also holds memories, but it focuses on where something is located compared to other things around it. By analyzing the brain activity of our rats, we found that the $\mathrm{mPFC}$ held the information about what the lever looked like, whereas the $\mathrm{HC}$ held the information about whether the lever was on the left or the right.

Whenever the rats in our experiment pushed the correct lever, the mPFC and the $\mathrm{HC}$ were both working or "jumping rope" to the pace of the hippocampal theta rhythm. Because the rhythms of the two brain areas matched, the information from the mPFC and the HC could be combined to find a solution to the problem of which lever to push. This is similar to the example of 
two friends "combining" to jump rope successfully at the same time if they are in the same rhythm. Whenever the rats did not push the correct lever, we found that the cells in the mPFC were not "jumping rope" to the pace of the hippocampal theta rhythm. This meant that the information in the mPFC and that in the $\mathrm{HC}$ could not be added together, and the rats could not solve the problem, similar to what would happen if your friend did not match your jumping rhythm and the jump-rope game ended (as in Figure 1B). Overall, we found that our hypothesis was right! When the mPFC and HC were in sync, the rats played the game correctly; when the two brain areas were out of sync, the rats failed at the memory task.

\section{DISCUSSION: PLAY AGAIN ANOTHER DAY!}

The mPFC and the $\mathrm{HC}$ also work together in humans when we want to solve a problem. Look at the child playing a matching card game in Figure 4. The goal of the game is to find two cards that match, when only two cards can be flipped over at a time. In Figure 4A, he has already flipped over a Cat card in the lower right corner and is in the middle of flipping over a Snake card near the center right. Because these two cards do not match, he flips them both back over to conclude the turn. Then, he starts the next turn by turning over a brand new card. As you can see in Figure 4B, the child flips over a Snake card on the left. He then thinks about this card in Figure 4C. He remembers

FIGURE 4

The matching card game. A. The boy compares a Cat card in the lower right with a Snake card in the center right. He finds they do not match and ends the turn by flipping both cards back over. B. Next, the boy flips over a new Snake card on the left. C. The boy remembers seeing a Snake card before, with his medial prefrontal cortex, and he remembers where he saw the card, with his hippocampus. D. The boy flips over the old Snake card he originally found in A. and correctly matches the two Snake cards together.

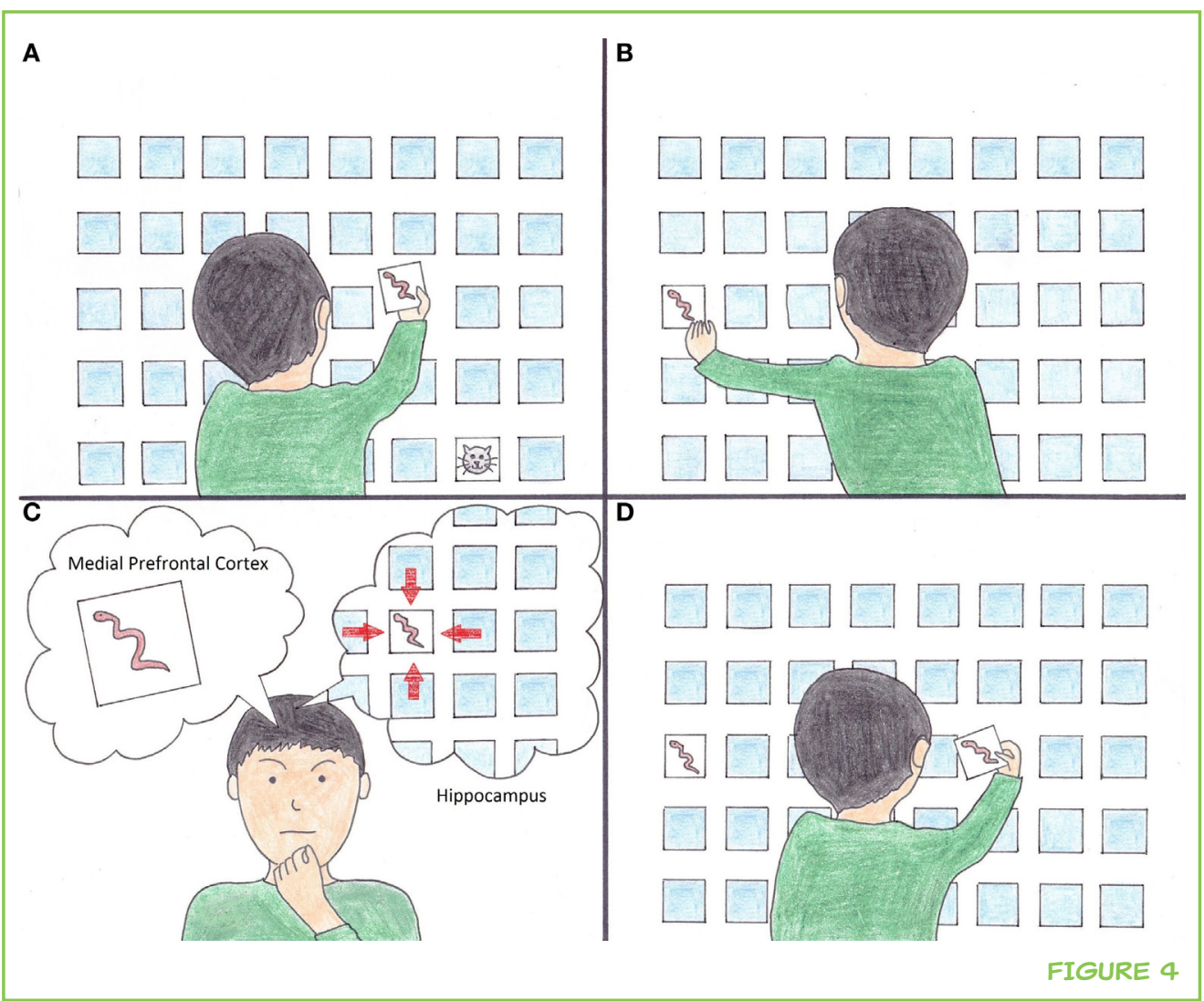


seeing the Snake card in the past using his $\mathrm{mPFC}$, and he remembers where the Snake card is located using his HC. Finally, in Figure 4D, the information he has from his mPFC and his $\mathrm{HC}$ are put together, allowing the boy to solve the problem and find two matching cards. He matches the new Snake card on the left with the Snake card on the right. Just like in rats, the mPFC and the $\mathrm{HC}$ in the boy's brain communicated by "jumping rope" at the same rhythm, so that the puzzle could be solved. If the mPFC and the $\mathrm{HC}$ were not communicating or "jumping rope" at the same rhythm, the boy would not have realized that he had seen the Snake card before in a different location and he would have missed matching the cards during this turn.

Think about a basketball team. The goal of everyone on the team is to get the ball in the opponent's basket. However, not everyone does the same job. One teammate could dribble the ball and look for a weakness in the defense. Another teammate could move in a way that draws defenders away from the ball. Another team member could stand under the basket and be ready to tip in rebounding shots. Every team member plays a different role, but they must communicate so that they can work together to get the ball in the basket. If they do not work together in this way, the team will make a mistake (like passing the ball to someone who is not ready) and lose the possession. Just like a team of basketball players, the different parts of the brain all have different jobs and need to communicate to work together. In the case of our experiment, the $\mathrm{mPFC}$ and the HC communicated using the hippocampal theta rhythm, which let these two brain areas combine their information and allowed the rat to reach its goal (getting a sweet treat).

The way that brain areas interact is important to study because if we know how different parts of the brain work together, it will be easier to pinpoint the areas to target when helping people whose brains are not communicating properly. For example, Parkinson's disease can cause problems in controlling movement, thoughts, and emotions. A person with Parkinson's may feel a bit like he is trying to ride a bicycle while pedaling and braking at the same time-he is not really able to control when he stops or goes. Because Parkinson's disease can cause so many different issues that are typically regulated by many different areas of the brain, treatment might seem extremely complicated. However, through examining how the brain areas connect, scientists realized there was one area of the brain called the basal ganglia that was connected to all of the other brain areas that controlled movement, thoughts, and emotions. They discovered that Parkinson's was actually only causing problems in the basal ganglia, rather than many different areas of the brain. This understanding allowed for better therapies to be developed as scientists began targeting the basal ganglia in Parkinson's disease treatment. By better understanding the brain, we can help to build a foundation for future innovations in medicine, like with Parkinson's disease, and beyond. 
We discovered through our experiment that the MPFC and HC communicate when memory problems are solved correctly, and that these two brain areas achieve this through the hippocampal theta rhythm. But the mPFC and the $\mathrm{HC}$ are not the only parts of the brain that must work together. In order for animals or humans to do anything, all the different parts of the brain have to be talking or "jumping rope" with each other at different rhythms. We hope that, in the future, all the different parts of your brain will work together to help you create amazing, innovative, and inspiring scientific discoveries!

\section{ORIGINAL SOURCE ARTICLE}

Hyman, J. M., Hasselmo, M. E., and Seamans, J. K. 2011. What is the functional relevance of prefrontal cortex entrainment to hippocampal theta rhythms? Front. Neurosci. 5:24. doi:10.3389/fnins.2011.00024

SUBMITTED: 18 May 2017; ACCEPTED: 27 October 2017;

PUBLISHED ONLINE: 16 November 2017.

EDITED BY: Lauren Jantzie, University of New Mexico, United States

CITATION: Zha KR, Hyman J and Hyman JM (2017) The Jump-Roping Brain. Front. Young Minds 5:61. doi:10.3389/frym.2017.00061

CONFLICT OF INTEREST STATEMENT: The authors declare that the research was conducted in the absence of any commercial or financial relationships that could be construed as a potential conflict of interest.

COPYRIGHT @ 2017 Zha, Hyman and Hyman. This is an open-access article distributed under the terms of the Creative Commons Attribution License (CC BY). The use, distribution or reproduction in other forums is permitted, provided the original author(s) or licensor are credited and that the original publication in this journal is cited, in accordance with accepted academic practice. No use, distribution or reproduction is permitted which does not comply with these terms.

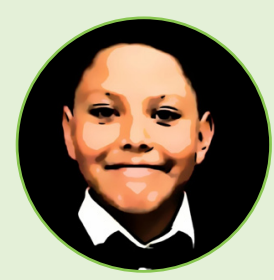

\section{REVIEWED BY}

JACOB, $\|$ YEARS OLD

I am Jacob. My favorite subjects are reading and language arts. I like to play basketball and football. My favorite teams are the New England Patriots and Oklahoma City Thunder. I also enjoy playing with my three dogs, riding my dirt bike, and traveling with my family. 


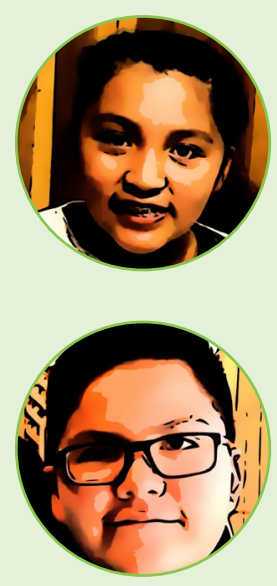

\section{KALAMITY, $\|$ YEARS OLD}

My name is Kalamity, and I am 11 years old. My favorite subjects in school are reading and science. When I grow up I want to be a veterinarian. I also enjoy riding my horses and playing with my four dogs.

\section{MATTHEW, 13 YEARS OLD}

My name is Matthew, and I am 13 years old. My favorite subjects in school are math and science. When I grow up I want to become an engineer. I enjoy tending to my livestock on our ranch with my parents and little brother. I also enjoy riding my dirtbike and playing with my dogs.

\section{AUTHORS}

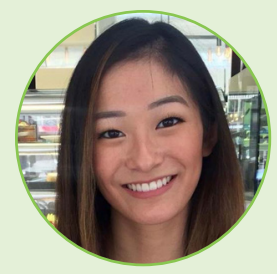

\section{KATE R. ZHA}

Kate R. Zha graduated with a Bachelor of Science from UCLA and now works in Dr. James Hyman's lab at UNLV. Some of her favorite things include science, mystery books, and mint chocolate chip ice cream. In her spare time, she likes to play with her two dogs, Oliver and Bella, bake cookies, and dance like no one's watching.

\section{JENNIFER HYMAN}

Jennifer Hyman studied biology and psychology at UBC in Canada. She also learned how to test for nerve and brain problems at BCIT, using tests such as the EEG. She is currently a stay-at-home mom to two kids, one of whom was named after a soap opera character. For fun, she draws in her art journal, searches for new recipes, gardens, brainstorms photoshoot ideas, and goes to the beach.

\section{JAMES M. HYMAN}

Dr. James M. Hyman is a professor at the University of Nevada Las Vegas. He has a lab that studies how the brain learns and how different brain areas communicate. He has two children and two dogs (one that weighs 175 lbs! - the dog, not the kids). He likes to spend time hiking with his family and dogs, playing drums, biking to campus (always wear a helmet!), and he knows all the words to Frozen's "Let It Go.” *james.hyman@unlv.edu 